\title{
Prevalence of Mastitis and Associated risk factors in Jimma Town Dairy Farms, Western Ethiopia
}

\author{
Bayush Tesfaye and Ataro Abera*
}

Jimma University, College of Agriculture and Veterinary Medicine, School of Veterinary Medicine, Jimma, Ethiopia

${ }^{*}$ Corresponding author: Abera A, Jimma University, College of Agriculture and Veterinary Medicine, School of Veterinary Medicine, Jimma, Ethiopia, Tel: +251473450172, E-mail: atishabe.dvm@gmail.com

Citation: Tesfaye B and Abera A (2018) Prevalence of Mastitis and Associated risk factors in Jimma Town Dairy Farms, Western Ethiopia. J Vet Sci Ani Husb 6(3): 304. doi: 10.15744/2348-9790.6.304

Received Date: June 21, 2018 Accepted Date: August 22, 2018 Published Date: August 24, 2018

\begin{abstract}
Across sectional study of epidemiological risk factors and associated bacterial pathogens was conducted on 216 lactating dairy cows in jimma town from Oct. 2016 to April 2017 to determine the overall prevalence rate, associated bacterial pathogens and to assess effect of risk factors on prevalence of mastitis. Upon physical examination of udder and teats the prevalence of clinical mastitis was $2.3 \%$ at cow level and $0.96 \%$ at quarter level. Using the California mastitis test (CMT) for detection of sub clinical mastitis, the prevalence of sub clinical mastitis at cow level and quarter level was 60.65 and $38.4 \%$ respectively. The overall prevalence of mastitis was 62.96 . Out of $323(38.4 \%)$ CMT positive quarters with evidence of sub clinical mastitis, the quarter infection rate for the right rare quarter was highest (41.3\%) followed by left rear (38.8\%), right and left front (each 36.7\%). Up on microbiological examination of milk samples for both clinical and subclinical quarters, out of a total of 331 cultured, 271(81.9\%) yielded bacteria whereas 60(18.1\%) yielded no bacteria. A total of 263 bacterial pathogens were isolated whereas 8 were mixed infections with more than two different colonies. The main bacterial pathogens isolated were coagulase negative staphylococci (CNS) (26.6 \%), Staphylococcus aureus (24.7\%), Escherichia coli (13.31\%), Streptococcus species (9.13\%), and Pseudomonas aeruginosa (8.8\%). Other bacteria isolated with low isolation rate were micrococcus species (3.04\%), Corynebacterium species (3.4\%), Actinomyces pyogenes (3.8\%), Bacillus species (3.42\%) and other gram negative rods (3.8\%). Host factors such as breed, age parity and lactation stage had significant effect on the prevalence of mastitis ( $\mathrm{p}<0.05)$. Managemental and environmental factors such as bedding, ventilation, frequency of barn cleaning, udder washing and use of communal towel had significant effect on the occurrence of mastitis $(\mathrm{p} \ll 0.05)$. Whereas milking practice, drainage had insignificant effect on the prevalence of mastitis ( $p>0.05)$.
\end{abstract}

Keywords: Mastitis; Prevalence; Pathogens; Risk Factors; Lactating Cow; Jimma

\section{Introduction}

Ethiopia has the largest livestock population of any African country, with an estimated 35 million tropical livestock units; this includes 31 million cattle, 42 million sheep and goats, 7 million equines, 1-2 million camels, and more than 53 million chickens. Cow represents the largest proportion of cattle population of the country according to the food and agriculture organization $42 \%$ of the total cattle heads for the private holding are milking cows [1]. Holstein Friesian is one of the most important dairy breed in the world. Each of these breeds has been selected for its milk producing ability in contrast in the tropics the breeds of cattle are usually bos indicus [2]. Milk produced from these animals provides an important dietary source for the majority of rural as well as a considerable number of the urban and per-urban population however; milk production often does not satisfy the country's requirements [5].

Mastitis is an inflammation of the mammary glands; it causes a great loss or reduction in animal productivity than any disease of dairy cattle. It is the costliest disease and remains a series problem for dairy industry for its influences both on the quantity and quality of milk produced it causes a marked fall in milk yield and is a cause of culling of animals [3]. Most estimates show that on the average affected quarter suffer a $30 \%$ reduction in productivity and affected cow is estimated to lose a $15 \%$ of its production per lactation [4]. Mastitis is a disease that affects a large number of dairy cattle throughout the world.

Mastitis is a complex disease that generally involves between managements practices and infectious agents. Various infectious agents are involved as a causative agent of mastitis with bacterial pathogens covering the great share. These bacteria are widely spread in the environment of dairy cow constituting threat to the mammary gland. The severity of the disease is determined by the 
nature of infecting bacteria, the natural mechanism of resistance of the cow and to some degree by stresses placed on the mammary glands by milking practices and environmental factors [5].

\section{Statement of the problem}

In Ethiopia mastitis has long been known. Different researchers the disease has not been studied widely and the information related to the economic loss and the overall prevalence of the disease is inadequate. Because at the study time, the study on mastitis was not enough in many areas of the country. For example, as we know in Jimma town many dairy farms are their but at that time there is no any study about mastitis in Jimma town. However, studies conducted by different researchers in various parts of the country indicated high prevalence of the disease [6,7]. This study was conducted in Jimma town from October 2016 to April 2017 with the following objectives:

$\checkmark$ To access the overall prevalence of the mastitis in lactating dairy cows in Jimma dairy farms

$\checkmark$ To assess the effect of risk factors associated with the occurrence of mastitis and

$\checkmark$ To isolate and identify the major causes of bovine mastitis in the area.

\section{Materials and Methods}

\section{Study animals}

A total of 216 cows from 36 farms were included in this study both indigenous zebu and cross-breed dairy cows. The majority of cows were cross breeds. The blood level of the exotic was $50-88 \%$ and more than $99 \%$ of the cross breeds were Holstein Frisian breeds. All animals sampled were lactating. The management systems of the farm were intensive

\section{Study design}

A cross-sectional study was conducted from October 2016 to April 2017 by collecting milk samples from lactating cows in jimma town and questionnaire was conducted. Physical examination of the udder was conducted for the presence of clinical mastitis, anomalies and the results were recorded. Milk samples were collected aseptically and transported in an icebox to the laboratory for microbiological analysis. CMT was conducted on collected milk samples and the result was recorded. Microbiological culturing of CMT positive samples was done for isolation and identification of bacteria. For laboratory techniques and data collection standard procedures was followed [8].

\section{Sample Size Determination}

Sample size was determined according to Thrusfield by taking $20 \%$ prevalence using the formula [9]:

$$
\mathrm{n}=\frac{1.96^{2} \mathrm{p}_{\exp }\left(1-\mathrm{p}_{\mathrm{exp}}\right)}{\mathrm{d}^{2}}
$$

Then, a total of 216 lactating cows from 36 dairy farms were included in the study which is less by 30 lactating cows because of inability to get more lactating cows.

Where, $\mathrm{n}=$ required sample size

$\mathrm{P}_{\exp }=$ expected prevalence

$\mathrm{d}=$ desired absolute precision, if $\mathrm{p}_{\exp }=20 \%$ and $\mathrm{d}=0.05$, then $\mathrm{n}=246$

\section{Study Methodology}

Physical examination of udder: Any physical abnormalities such as swelling of the udder, presence of lesions or anatomical malformations were recorded. The milk was examined for its color, odor, consistency and other abnormalities. Previous history of mastitis and treatment was recorded.

Milk sample collection: Procedures for collecting milk samples was according to Schalm et al. [5]. The time chosen was before milking since there is an elevation in somatic cell count immediately after milking and for at least six hours thereafter. Udders and especially teats was cleaned and dried before sample collection. Each teat end was scrubbed vigorously with a pledged of cotton or gauze sponge moistened with $70 \%$ ethyl alcohol. Scrubbing the tests on the far side of the udder first, then those on the near side will avoid recontamination of teats during scrubbing. A separate pledged or sponge was used for each teat. Teats toward sample collection was sampled first and then far ones. The first few streams of milk were discarded and $20 \mathrm{ml}$ of milk collected in to the vial, then the sample placed in an icebox and transported to the laboratory for analysis.

California mastitis test (CMT): California mastitis test was carried out using the method described by Schalm et al. [5]. A squirt of milk, about $2 \mathrm{ml}$ from each quarter was placed in each of two shallow cups in the CMT paddle. An equal amount of the commercial reagent was added to each cup. A gentle circular motion was applied to the mixtures, in a horizontal plane for 15 second. The result was interpreted and scored from 0-3.

Bacteriological investigation: Various types of media were prepared and used for growing the organisms or carrying out subsequent procedures that aided in species identification such as, blood agar, MacConkey and mannitol salt sugar. 


\section{Influence of breed, sex and age of cattle on the prevalence of tuberculosis}

All the milk samples were processed and analyzed bacteriologically according to Carter the sample kept refrigerated and allowed to equilibrate room temperature the samples were then shaken [10]. One standard loopful (0.01) 0f the sample was transferred to blood agar, nutrient agar, and MacConkey agar plates. The plates were then incubated at $37^{\circ}$ for $18-24$ hours and growth observed.

Examination of the blood agar plates for the presence of growth, colonial morphology, presence or absence of hemolysis was done at 24, 48 and 72 hours post incubation. From those plates which showed growth of organisms, representative colonies were stained by the Gram's Method to identify the morphology the staining property of the grown organism. The colonies were isolated on to media on which representative colony of single organism was sub cultured from primary media. Media such as Mannitol salt agar and MacConkey were used on the basis of cultural and staining properties and results of some primary test.

\section{Data analysis}

Data of physical examination of udder, CMT scores, culture conditions and results of questioner survey were recorded on a prepared format and to an excel. The possible association of different host and management factors to the prevalence of mastitis was analyzed using the chi-square $\left(\chi^{2}\right)$ test using Stata 8.0 soft ware.

\section{Results}

A total of 216 lactating cows from 36 dairy farms were examined for presence of clinical and sub clinical mastitis. The study included 31 local breed cows and 185 crossbreed dairy cows. Results for physical examination of the udder, CMT scores, bacteriological examination of milk samples and questionnaire survey was performed.

\section{Physical examination}

Physical examination and visual inspection was conducted on udder, teats and milk of 216 lactating cows and abnormalities such as clinical mastitis, blind teat and change in milk were observed. Of the total examined, 17 animals (7.87\%) had one or more blind quarter.

\section{Screening test}

From the total animal examined $5(2.32 \%)$ were clinically affected and $131(60.65 \%)$ were sub clinical cases or CMT positive at animal level (Table 1). Out of clinically affected animals two of them showed acute mastitis evidenced by warm, swollen, painful, abnormal secretion and decreases in secretion with minor systemic involvement. One animal showed subacute mastitis and two animals had history of chronic mastitis.

\begin{tabular}{|c|c|c|}
\hline Form of mastitis & Cow level prevalence $\mathbf{( N = 2 1 6 )}$ & Quarter level prevalence $\mathbf{( N = 4 8 1 )}$ \\
\hline Clinical & $5(2.3 \%)$ & $8(0.95 \%)$ \\
Sub clinical & $131(60.65 \%)$ & $323(38.4 \%)$ \\
\hline Overall & $136(62.9 \%)$ & $331(39.4 \%)$ \\
\hline
\end{tabular}

Out of 841 quarters examined 323 (38.4\%) and 8 (0.95\%) were CMT positive for sub clinical and clinical mastitis, respectively, by considering CMT scores 0 as negative and 1, 2, 3 as positive. Out of CMT positive 323 (38.4\%) quarters which showed evidence of sub clinical mastitis, the quarter infection rate for the right rare quarter showed highest rate of intra-mammary infection (41.3\%) followed by left rear (38.8\%), right and left front (36.7\%) (Table 2).

\begin{tabular}{|c|c|c|c|}
\hline Quarter & No & examined positive & Prevalence \\
\hline Right front & 215 & 79 & 36.7 \\
Right rare & 213 & 88 & 41.3 \\
Left front & 207 & 76 & 36.7 \\
Left rare & 206 & 80 & 38.8 \\
\hline Total & 841 & 323 & 38.4 \\
\hline
\end{tabular}

Table 2: Quarter prevalence of sub clinical intra-mammary infection

\section{Bacteriological analysis}

A total of 331 milk samples from 136 cows were cultured and 271 sample (81.9\%) yielded bacteria whereas 60 (18.1\%) yielded no bacteria. Milk samples from CMT positive quarters were cultured and 263 bacterial isolates were identified. The isolates were 8 from clinical and 255 from sub clinical mastitis cases. The relative prevalence rates of various bacterial species of organisms that were isolated from both clinical and sub clinical mastitis are shown on (Table 3). Staphylococcus species were the predominant isolates of all, with coagulase negative staphylococci being the most frequent with isolation rates of 26 (62\%) followed by Staphylococcus aureus (24.7\%) and E. coli (13.31\%). The least isolation rate was that of micrococcus species (3.04\%). Pseudomonas aeruginosa, bacillus spp and streptococci were isolated from both clinical and sub clinical mastitis. Corynebacterium spp, Actinomyces pyogenes and other Gram-negative rods were isolates from only sub clinical mastitis. 


\begin{tabular}{|c|c|c|c|c|}
\hline Microorganisms & Clinical & Sub clinical & Total & Percentage \\
\hline Staphylococcus aureus & 3 & 62 & 65 & 24.7 \\
\hline Coagulase Negative & 0 & 70 & 70 & 26.6 \\
\hline Micrococcus spp & 1 & 7 & 8 & 3.04 \\
\hline Streptococcus spp & 1 & 23 & 24 & 9.1 \\
\hline Actinomyces pyogenes & 0 & 10 & 10 & 3.8 \\
\hline Corynebacterium spp & 0 & 9 & 9 & 3.4 \\
\hline Bacillus spp & 1 & 8 & 9 & 3.4 \\
\hline E. coli & 1 & 34 & 35 & 13.3 \\
\hline Pseudomonas aeruginosa & 1 & 22 & 23 & 8.8 \\
\hline Other Gram negative rods & 0 & 10 & 10 & 3.8 \\
\hline Total & 8 & 255 & 263 & 100 \\
\hline
\end{tabular}

Table 3: Overall prevalence rates of bacterial isolates identified from mastitis cases

\section{Epidemiological factors in relation to mastitis}

Host risk factors: Prevalence of mastitis related to specific risk factors was determined. Breed, age, parity and stage of lactation had a significant effect on the prevalence of mastitis (Table 4).

\begin{tabular}{|c|c|c|c|c|}
\hline Host risk factor & Total number of animals & Mastitis status (clinical and sub clinical) & $\chi^{2}$-Value & p-value \\
\hline \multicolumn{5}{|l|}{ Breed } \\
\hline Local & 31 & $10(7.4)$ & \multirow{2}{*}{$\begin{array}{l}28.0 \\
126\end{array}$} & \multirow{2}{*}{$\mathrm{p}=0.002$} \\
\hline Local $x$ Holstein Frisian & 185 & $126(92.6)$ & & \\
\hline \multicolumn{5}{|l|}{ Age } \\
\hline Young adult & 90 & $58(42.6)$ & \multirow{3}{*}{$\begin{array}{l}16.0 \\
737\end{array}$} & \multirow{3}{*}{$\mathrm{p}=0.041$} \\
\hline Adult & 27 & $19(13.97)$ & & \\
\hline Old & 99 & $59(43.4)$ & & \\
\hline \multicolumn{5}{|l|}{ Lactation stage } \\
\hline Early & 67 & $50(36.8)$ & \multirow{3}{*}{$\begin{array}{l}25.5 \\
620\end{array}$} & \multirow{3}{*}{$\mathrm{p}=0.001$} \\
\hline Mid & 61 & $32(23.5)$ & & \\
\hline Late & 88 & $54(39.7)$ & & \\
\hline \multicolumn{5}{|l|}{ Parity } \\
\hline Few & 23 & $14(10.3)$ & \multirow{3}{*}{$\begin{array}{l}11.1 \\
859\end{array}$} & \multirow{3}{*}{$\mathrm{p}=0.025$} \\
\hline Moderate & 53 & $37(27.2)$ & & \\
\hline Many & 140 & $85(62.5)$ & & \\
\hline
\end{tabular}

Cows at age group of young adult, adult and old had an infection rate of 42.6, 13.97, and 43.4\% respectively. Cows of age 3-5 year was considered as young adult, cows of age group from 6-10 years was considered as adult and greater than 10 years as old animals; above 10 years were the most affected groups.

The prevalence of mastitis was significantly affected by the stage of lactation $(\mathrm{p}<0.05)$. Cows at different stages of lactation had an infection rate of $36.8,23.5$ and $39.7 \%$ for early, mid and late lactation stages, respectively. It was highest for greater than 8 months of lactation. Cows were considered as in early lactation stage from $1^{\text {st }}$ to $3^{\text {rd }}$ month; mid lactation stage from $4^{\text {th }}$ to $7^{\text {th }}$ month and cows in late lactation stage were greater than 8 months.

Parity had significant effect on infection rate $(\mathrm{p}<0.05)$. The percentage of infection was $10.3,27.2$ and $62.5 \%$ for cows who had few, moderate and many calves, respectively. Considering cows with greater or equal to 3 calves as few cows with 4 to 7 calves as moderate and cows with greater than 7 calves as many.

Management and environmental risk factors: Management factors such as type of housing, frequency of barn cleaning, presence of ventilation, drainage and bedding were assessed for their effect as risk of udder infection (Table 5). Animals examined were managed under intensive management system. Ventilation had significantly influenced the status of mammary infection ( $\mathrm{p}<0.05)$. There was higher incidence of mastitis in poorly ventilated barns than ventilated barns with relative infection rate of 46.67 and $32.3 \%$ respectively. Bedding also had significant effect on prevalence of mastitis $(\mathrm{p}<0.05)$; cows in farms with bedding suffered a prevalence rate of $35.9 \%$ against farms without bedding $(47.29 \%)$. 


\begin{tabular}{|c|c|c|c|c|c|c|}
\hline \multirow{2}{*}{ Management } & \multicolumn{2}{|c|}{ Status of mastitis } & \multirow{2}{*}{ Group total } & \multirow{2}{*}{ prevalence } & \multirow{2}{*}{ Chi-square } & \multirow[b]{2}{*}{ p-value } \\
\hline & Positive & Negative & & & & \\
\hline \multicolumn{7}{|l|}{ Housing condition } \\
\hline With ventilation & 31 & 65 & 96 & 32.3 & 14.86 & $\mathrm{P}=0.001$ \\
\hline Without ventilation & 56 & 64 & 120 & 46.67 & & \\
\hline With drainage & 45 & 80 & 125 & 36 & 5.92 & $\mathrm{P}=0.051$ \\
\hline Without drainage & 40 & 51 & 91 & 44 & & \\
\hline With bedding & 51 & 91 & 142 & 35.9 & & \\
\hline Without bedding & 35 & 39 & 74 & 47.3 & 6.74 & $\mathrm{P}=0.034$ \\
\hline \multicolumn{7}{|l|}{ Floor } \\
\hline Concrete & 49 & 30 & 79 & 22.7 & \multirow{2}{*}{14.33} & \multirow{2}{*}{$\mathrm{P}=0.002$} \\
\hline None-concrete & 99 & 38 & 137 & 45.8 & & \\
\hline \multicolumn{7}{|l|}{ Barn hygiene } \\
\hline Cleaning $2 x /$ day & 76 & 106 & 182 & 41.8 & \multirow{2}{*}{46.24} & \multirow{2}{*}{$\mathrm{P}=0.000$} \\
\hline Cleaning $>2 x /$ day & 15 & 19 & 34 & 44.1 & & \\
\hline \multicolumn{7}{|l|}{ Milking practice } \\
\hline Udder washing & 5 & 6 & 11 & 45.5 & \multirow{2}{*}{0.04} & \multirow{2}{*}{$\mathrm{P}=0.980$} \\
\hline No udder washing & 79 & 126 & 205 & 38.5 & & \\
\hline $\begin{array}{l}\text { Udder wash with warm } \\
\text { water }\end{array}$ & 22 & 47 & 69 & 31.9 & 13.22 & $\mathrm{P}=0.001$ \\
\hline $\begin{array}{l}\text { Udder wash with cold } \\
\text { water }\end{array}$ & 62 & 85 & 147 & 42.2 & & \\
\hline Use of towel & 0 & 8 & 8 & 0 & \multirow{2}{*}{10.27} & \multirow{2}{*}{$\mathrm{P}=0.006$} \\
\hline No use of towel & 83 & 125 & 208 & 39.9 & & \\
\hline Milking $2 x /$ day & 80 & 126 & 206 & 38.8 & 0.20 & $\mathrm{P}=0.903$ \\
\hline Milking 3x/day & 3 & 7 & 10 & 30 & & \\
\hline
\end{tabular}

Table 5: Management risk factors in relation to mastitis

Barns which lacked drainage were affected than those which has well-constructed drainage and statistically insignificant to mastitis infection $(\mathrm{p}>0.05)$. Floor had statistical effect on mastitis.

In all farms it was found that hand milking was the only practice. In most farms cows are milked twice; early in the morning and late afternoon and few farms milk 3 times per day; early morning, midday and night. Most of the farms they practice udder washing with water only few don't wash udder. In all the farms they don't use pre-milking and post milking disinfection. In most farms, milking is conducted by employed labor.

\section{Discussion}

Prevalence of clinical and sub clinical mastitis: In the present study the overall prevalence of mastitis in Jimma dairy farms was $62.92 \%$. This finding is comparable with that of Biru reported $63.4 \%$. But it is lower than the finding of Zerihun who reported $68.1 \%$ over all prevalence $[11,13]$.

The prevalence of clinical mastitis at cow level was $2.32 \%$ and sub clinical mastitis $60.65 \%$. The prevalence of clinical mastitis is comparable with Huesin who reported prevalence rate of $2.7 \%$ but lower than reported by Tolossa who reported 6.29 . On the other hand, Tola reported sub clinical mastitis at the rate of 65.45 higher than the present study $[6,7,13]$. Robertson reported that the sub clinical mastitis is usually higher than the clinical mastitis duet to difference mechanism of mammary gland is acting to minimize the severity of the disease. In the farms under investigation the recommended hygienic procedures including post milking dip and dry cow therapy were absent, use of separate towel and hygiene of the environment of dairy cow were given less attention [14].

Prevalence of mastitis in the quarters: Quarter prevalence of mastitis was $38.4 \%$ which agrees with the finding of Nesru et al. who reported the quarter prevalence rate of 37 [15]. The present finding was higher than reports made by Tolossa and Sori who reported 30.6 and $27.8 \%$, respectively. Radostitis et al. related the variation in quarter prevalence of mastitis with the variation in the overall prevalence of disease in the herd $[4,13,16]$. Comparisons of the relative infection rates of different quarters indicted highest inflation rate in the right rear quarter $(41.3 \%)$ followed by the left rear quarters (38.8\%), other being relatively lower. This finding is in agreement with Shbeshi who reported grater inflation rate in hind quarters [17]. This would be associated with the high production capacity of the hind quarters that are reported to yield $60 \%$ of production [5]. Likelihood of hind quarters to be contaminated is high. The right might also be the first to be grasped by milkers as routine milking procedures. 
Bacterial isolation: The bacteriological findings indicate that Staphylococcus spp. was the major pathogen isolated from both clinical and sub clinical mastitis. The highest prevalence of $S$. aureus is attributed to the wide distribution of organism inside the mammary gland and on the skin of the tests or udder, in areas where hand 6.3 Bacterial isolation: The bacteriological findings indicate that Staphylococcus spp. was the major pathogen isolated from both clinical and sub clinical mastitis. The highest prevalence of $S$. aureus is attributed to the wide distribution of organism inside the mammary gland and on the skin of the tests or udder, in areas where hand milking has been practiced [4]. S. aureus has capacity to penetrate deep foci and protected by a tissue from being attacked by drugs, this limits cure rate making the organism to assume a position of major importance. The milking routine in the study area also favors the contagiousness of $S$. aureus as effective udder washing, drying, post milking teat dip, and inter-cow-hand washing disinfections were absent. Coagulase negative staphylococci (CNS) species $26 \%$ was the most dominant bacteria in present study. Variable reports existed on these pathogens, Biru reported a prevalence rate of $41.7 \%$, but, Tola reported as low as $9.63 \%[7,11]$.

Micrococcus species accounted for 3.04\% which partially agrees with the findings of Sori who reported 6.7\% [16]. But as high as $15.4 \%$ by Zerihun and $17.9 \%$ by Shbeshi had been reported from cases of sub clinical mastitis from different dairy herds [12,17]. The lack of post milking teat dip in the farms could be the predisposing factor. Post milking teat, udder washing and drying prior to milking are effective in controlling coagulase negative staphylococci and Micrococcus species [3].

The incidence of Streptococci species during this study was $9.13 \%$. The relative importance of these genera as an etiological agent of mastitis was lower that reported by Zerihun and Sori who reported relative prevalence rates of 14.18 and $27 \%$ in dairy cows respectively $[12,16]$. The lower isolation rate of streptococcus in this study might be due to the wide spread use of penicillin for the treatment of mastitis in the area. It was indicated that mastitis caused by streptococcus is liable to eradication via use of penicillin $[5]$.

In this study mastitis caused by Corynebacterium species accounted for 3.42\% which corresponds with Tola and Biru who reported an isolation rate of $4.2 \%$ and $4.55 \%$ respectively. In the herds under the present study, there was no post milking teat dip, udder washing and drying was irregular. These contribute to the higher isolation rates of Corynebacterium species [4,7,11].

Bacillus species were isolated in $3.42 \%$ of cases. This is consistent with the reports of Sori who found isolation rate of $4.48 \%$ but lower than that of Haile and higher than Tola who reported 11.56 and $2.96 \%$ respectively $[7,16,18]$. Rate of infection with Bacillus species is higher in dry cows and occurs following contamination during unhygienic therapy since most species are saprophytes [5].

Escherichia coli were isolated from clinical cases and a sub clinical case (13.31) which was the lowest compared to previous reports with 34.9 and $17.04 \%$ respectively [7,18]. Zerihun and Mekuria reported 11.5 and $3.64 \%$ respectively [12,19]. E. coli is a poor contagious bacterium, and the highest prevalence of other pathogens of mastitis particularly Staphylococcus, Streptococcus and Corynebacterium lead to rise in somatic cell count of milk which limits the multiplication of the coliforms has also shown that Pseudomonas is intermittently shed from the udder and does not frequently appears in milk [4].

Of all isolates, contagious pathogens showed greater frequency than others. Most of the infections were mixed and caused by more than one species of organism. This could be explained from poor milking and management practices and milkers who milk in more than one farm. The possible minimization of these organisms (and Streptococci) may be achieved by improving hygienic methods, antibiotic therapy and milking machine design [20]. The high population of pathogens or infection in the area both per cow and per quarter is one factor suggesting the economic significance of disease. This loss emanates from poor response to therapy or pathogens. A cow with one quarter harboring multiple infections had greater in production than a cow with a single pathogen.

From the total samples taken for bacteriological investigations, 60 (18.13) were negative for isolation. This is agreeing with Pearson and Mackie 18\%, as low as 3.14\% has also been reported by Haile [18,21]. Quarter milk samples which were positive for CMT screening could be bacteriologically negative. This may be due to the bactericidal properties of the inflammatory udder secretion which destroys the infecting bacteria thus they may not be found in milk with high leukocyte counts. Some pathogens like Staphylococcus aureus populations fluctuate in the milk from infected glands often during the infectious process which may bring concentration below a detectable level preventing bacteriologic culture [22].

Epidemiological risk factors: In order to device effective disease control program those factors which directly or indirectly affect the disease occurrence, severity and prognosis should be known so that correction of errors and improvements of draw backs be done [23]. In this respect possible interaction of mastitis with host factors and environmental factors were evaluated. That is, the possible association of breed, lactation stage, age and parity as well as the effects of housing, milking and related practices was studied.

The finding in the present study indicated that there was statistically significant difference in the prevalence of mastitis between local zebu and cross breeds. Radostitis concluded that high yielding cows are considered to be more susceptible to mastitis [4]. It was also indicated that the position of the teat and udder anatomy of the teat canal in these cows makes them exposed to teat injury. 
The incidence of mastitis in this area should the highest infection rate in cows having lactation stage of 8 months and above (Table 4) with an infection rate of $39.7 \%$. The lactation stage showed significance on prevalence of mastitis. Alemnew has also reported similar tends in mastitis infections [24]. The relatively higher prevalence of mastitis at the end of lactation stage was justified owing to the characteristic of milk which inhibits phagocytosis near and in drying period. On the other hand, at the initial stages of lactation, there is a higher risk of mastitis. The latter being associated with delayed diapedesis of neutrophils in to the mammary gland and persistency of infection acquired during the dry period to make the initial stage of lactation, more susceptible to infection. The infection rate $36.8 \%$ was recorded by this study for initial lactation stages [5].

The cows greater than 10 years old experienced the highest infection rate $43.4 \%$. This finding agrees with that of Radostitist who explained that older cows have largest teats and more relaxed sphincter muscles, which makes them liable to accessibility of infectious agents [4].

The finding that incidence of mastitis at different parity groups or cows with many calves $(>7)$ were at risk (62.5\%) of developing an udder infection than those with fewer $(<\mathrm{or}=3)$ calves $(10.3 \%)$.

In this study all examined cows were kept indoor. These include adequacy of bedding, slipperiness of floor, overcrowding, which all are related to udder infection. The finding that infection rates related to factors such as poorly ventilated barns (32.29\%) against ventilated (25.83\%), bedding (35.9\%) and without bedding (47.29\%) and with drainage (36\%) and without drainage (44\%) indicate that these risk factors contribute to the mastitis in a head. Ventilation minimizes environmental population of pathogens in the barn, provides fresh air and conditions the environment of the barn which could limit the survival and multiplication of the pathogens in the barn or on the animal [23]. The animal's urine, soft faces in the dirty fluids and contaminated wash water which harbor and possibly serve as a source of pathogens for mastitis can remove via drainage, which in its absence serve as a mastitis risk factor.

With tied housing systems, bedding plays an important role in the incidence of mastitis. In adequate bedding in tied housing systems may lead to serious situation in the case of mastitis. And also the bedding of the animals, unless regularly changed could serve as the site of the multiplication for mastitis pathogens. Bedding can be a major source of environmental contamination for teat. However, some farms, which use grass bedding, showed less infection rate that dry grass bedding has the least risk to mastitis in comparison to saw dust or straw bedding [4].

Although it was statistically significant $(\mathrm{p}<0.05)$, the prevalence of mastitis increased in cows housed without bedding. The role of the frequency of barn cleaning was also investigated. This finding was showed that barn cleaning was a risk factor. Those farms that were cleaned regularly contain crossbreed cattle, which were found to be more susceptible to mastitis, and the major isolates were contagious pathogens whose epidemiology is the infected udder and it is statistically significant $(p<0.05)$. The less attention given to the milking practices in different dairy farms [25]. The result of the study forwards the great necessity of use of separate towel for udder and teat drying after washing and the necessity of antiseptic solution in the wash water. These could be seen from the finding that cows in which no use of towel was faced greeter infection rates (39.9\%) that those which was used of udder drying. Mean somatic cell counts are lower in herds using separate towels and dry udder [26]. In this study, the infection rate was higher for cows which were washed prior to milking (45.45\%) than cows for which milking was practiced without washing (38.5\%). Mean in most of farms they practice udder washing with water only and drying but not regularly and few farms don't wash udder, hand washing between milking and disinfection were absent, use of separate towel for udder drying were absent and in all farms it was observed that there was no pre milking and post milking teat disinfection. So in most farms they do not practice correct milking procedure regularly. The absence of correct milking procedure regularity results best environment to mastitis causing pathogens. See the result as hand washing with soup is best than hand washing with only water having different result. And the infection rate was higher for cows, which were washed with cold water $(42.17 \%)$ than cow's udder washed with warm water (31.88\%)

\section{Conclusions}

The present study has shown that bovine mastitis is one of the major health problems in dairy farms in Jimma. The overall high prevalence of the disease in the farms, the isolated and identified pathogens involved is an indication of the great economic significance of the disease. Contagious pathogens followed by environmental pathogens were significant causes of mastitis infection. Breed, parity, age and lactation stage had influence on the occurrence of mastitis. Management factors such as ventilation, bedding, floor, barn hygiene, udder washing, and usage of towel showed significant effect on occurrence of mastitis. It was observed that there was no post milking teat disinfection and dry cow therapy. Udder washing and drying were used but not regularly practiced. Hand washing between milking and disinfection, use of separate towel for udder drying were absent. Early detection of mastitis was not possible as there was no strip cup examination, indirect test like CMT and white side test. The hygiene and other management practice of dairy cattle were not sufficient. Therefore, effectiveness of mastitis control can be achieved by improving milking, housing practices and other related management factors.

On the basis of the above findings, the following recommendations are forwarded.

$\checkmark$ The farm owners should be informed on risk factors of mastitis both host factor and management factors including hygienic measures during and after milking. 
$\checkmark$ The dairy cattle houses should be constructed in such a way that they are well ventilated and with proper gradient for drainage $\checkmark$ Information concerning factors such as age, lactation stage, parity number of the cows should be known prior to introduction of an animal to a farm.

D Owners should keep records about over all farm information and individual animals.

$\checkmark$ Animals chronically suffering from mastitis should be culled.

$\checkmark$ Regular screening and strip cup examination of the cows, cultural and other bacteriological examination of infected quarters should be conducted so that proper therapy is administered.

\section{Acknowledgements}

Above all thanks goes to GOD for his innumerable favors and fruit full results. I do have also special spiritual respect for his mother saint merry. My heartful thanks to my advisor Dr. Asefa Wakwoya, laboratory technicians Silesh Belew, Rahel Melaku and Gashhun G/Michael and to my family for technical support, encouragement and moral support. The cooperation and support by the owners of dairy cows during data collection and examination of animals are highly acknowledged.

\section{References}

1. FAO (1989) Milk, Milk production, hygiene and udder health. In animal production and health year book. 78: 69-72.

2. Mugrewa M (1989) Introduction. A Review of Reproductive Performance of Female Bos Indicus (Zebu) Cattle. ILCA Monograph 6: 1-4.

3. Belowey R (1985) Milk synthesis, and mastitis In: A Veterinary Book for Dairy Farmers, Farming press Ltd. Grat Britain.

4. Radostitis OM, DC Blood, CC Gay (1994) Mastitis In: Veterinary medicine: A text book of the disease of cattle, sheep, pigs, goats and horses ( $8^{\text {th }}$ Edn) W.B. Saunders Company, USA.

5. Schalm DW, EJ Caroll, C Jainn (1971) Bovine mastitis. Lea and Febiger Philadelphia, USA.

6. Hussein N (1999) Cross sectional and Longitudinal study of Bovine Mastitis in Urban and peri Urban dairy production systems in the Addis Ababa Region, Ethiopia. MSc thesis, Faculty of Veterinary Medicine, Addis Ababa University, DebreZeit, Ethiopia.

7. Tola T (1996) Discussion, Bovine Mastitis in indigenous Arsi Breed and Arsi Hlesteinrosses. DVM Thesis, FVM, A.A.U. Ethiopia.

8. Quinn PJ, ME Carter, B Markey, Carter GR (1999) Clinical veterinary microbiology, Mosby publishing, London.

9. Thrustfield M (1995) Veterinary epidemiology (2nd Edn) Wiley Blackwell Science, USA.

10. Carter GR (1984) Diagnostic Procedures in Veterinary Bacteriology and Mycology (4th Edn) Charles C. Thomas publisher, USA.

11. Biru G (1989) Major bacteria causing bovine Mastitis and their sensitivity to common antibiotics. Ethiopian J Agri Sci 11: 43-9.

12. Zerihun T (1996) A study on Bovine Sub-Clinical Mastitis at Stela Dairy Farm, DVM Thesis, FVM, A.A.U. Ethiopia.

13. Tolossa A (1987) A survey of bovine Mastitis around Kallu province, DVM Thesis, FVM, A.A.U. Ethiopia.

14. Robertson R (1985) The Use of EF Cow Milk NAGase test in Mastitis control programmer flow laboratories, Ayshire, Scotland.

15. Husein N, Yehualashet T, Tilahun G (1993) Prevalence of mastitis in different local and exotic breeds of milking cows. Proceedings of the fourth National Livestock Improvement Conference, IAR, Addis Ababa Ethiopia.

16. Sori H (1997) Bovine Clinical and sub clinical Mastitis in Indigenous Zebu and Cross breed Cattle in and Around Sebeta, DVM thesis, Faculty of veterinary medicine, Ethiopia.

17. Shbeshi G (1996) Discussion- prevalence and Anthology of sub-clinical Mastitis in Friesian Indigenous zebu crosses and indigenous zebu breeds of dairy cows in and around Bahir Dar, DVM, FVM thesis, FVAAU, Ethiopia.

18. Haile T (1995) Discussion: Bovine Mastitis in Indigenous zebu and Boran-Holestein crosses in South Wollo, DVM thesis, FVM, AAU, Ethiopia.

19. Mekuria M (1986) Prevalence and a etiology of Bovine Mastitis in Bahir Dar, DVM Thesis, FVM, AAU, Ethiopia.

20. Dodd FM (1982) Mastitis -progress on control. J Dairy Sci 66: 1773-80.

21. Pearson JKL, Mackie DP (1979) Factors associated with the occurrence, cause and out-come of clinical Mastitis in dairy cattle. Vet Rec 105: 456-63.

22. Vest Weber JG (1994) Staphylococcus aureus Mastitis part 2, Diagnostic Aids, Therapy, and control. Comp Cont Educ for Pract Vet 16: 217-25.

23. Clalence FM, Bergeron JA, Susan AM, Aiello E (1991) Mastitis in large Animal In: The Merck Veterinary Manual (7th Edn) Merck and Co. Inc. Rahway, NJ, USA.

24. Alemnew M (1999) Epidemiological and Bacteriological Investigation of Bovine Mastitis at Modjo state Owned Dairy Farm, DVM Thesis, FVM, AAU, Ethiopia. 25. Dodd FM (1983) Mastitis - progress on control J Dairy Sci 66: 1773-80.

26. Moxley JE, BW Kennedy, BR Downey, JST Bowman (1978) Survey of Milking Hygiene Practice and Their Relation Ships to Somatic cell counts Milk Production. J Dairy Sci 61: 1637-44. 
